\title{
Ciudades en la obra de Philip K. Dick y su adaptación al cine (II)
}

\author{
Javier RIVERO GRANDOSO \\ Departamento de Filología Románica, Filología Eslava y Lingüística General \\ Universidad Complutense de Madrid \\ javierriverograndoso@filol.ucm.es
}

Recibido: 05/03/2012

Aceptado: 11/05/2012

\section{Resumen $^{1}$}

La obra de Philip K. Dick (1928-1982) está siendo releída y reevaluada por la crítica académica, que cada vez está teniendo más en cuenta en sus estudios las narraciones del autor estadounidense. Cierta parte de culpa tienen las adaptaciones al cine de sus cuentos y novelas, que han conllevado una mayor difusión de su obra. En este trabajo nos centraremos en analizar la creación y representación de la ciudad en los textos literarios de Dick y su posterior adaptación a la gran pantalla para comparar la repercusión que cada medio tiene en la configuración del espacio urbano, con especial atención a las variaciones que se producen interesadamente para recrear tópicos del actual cine hollywoodiense.

Palabras clave: ciencia ficción, cine, ciudad, Philip K. Dick, Paycheck, Next.

Title: Cities in Philip K. Dick's literature and film adaptation (II)

\section{Abstract}

The work of Philip K. Dick (1928-1982) has now the attention of academic criticism. This has increased the studies on this author's works. This critical interest may be caused by the adaptation of his novels and short stories, which is also the reason for Dick's current great diffusion. In this paper we are going to analyze the creation and representation of the city in Dick's literary texts and their subsequent adaptation into films. We aim to compare the impact that each media has in the shaping of urban space, paying a special attention to variations due to the imitation of current Hollywood cinema topics.

Keywords: science fiction, cinema, city, Philip K. Dick, Paycheck, Next.

\section{Índice}

3.6. "La paga" (1953) / Paycheck (2003)

3.7. Una mirada a la oscuridad (1977) / A Scanner Darkly (2006)

3.8. "El hombre dorado" (1954) / Next (2007)

3.9. "La segunda variedad" (1953) / Asesinos cibernéticos 2 (Screamers: The Hunting) (2009)

3.10. "Equipo de ajuste" (1954) / Destino oculto (The Adjustment Bureau) (2011)

4. Las películas que vendrán

5. A modo de conclusión

${ }^{1}$ La primera parte de este artículo se publicó en el vol. 3, núm. 2 de Ángulo Recto. Disponible en: http://www.ucm.es/info/angulo/volumen/Volumen03-2/varia04.htm. 


\section{6. "La paga" (1953) / Paycheck (2003)}

Tras la buena acogida a nivel mundial de Minority Report, John Woo fue el encargado de llevar a la gran pantalla solo un año después otro cuento de Dick, "La paga". En él, Michael Jennings es un ingeniero que realiza un trabajo secreto para Construcciones Rethrick durante casi dos años, y para proteger la confidencialidad de su investigación eliminan todos los recuerdos de ese periodo de tiempo. El problema aparece cuando Jennings, al ir a cobrar su contrato, descubre que renunció a él por una bolsa con objetos cotidianos de poco valor. La policía lo persigue para averiguar qué labor desempeñaba en Rethrick, por lo que Jennings emprende una huida para entender qué sucedió durante los años que trabajó en la empresa. El personaje se sirve de los elementos que tiene en su bolsa para escapar y poder entrar en la sede de la compañía, lo que lo induce a pensar acertadamente en que el proyecto está relacionado con una máquina que le permite conocer el futuro.

La película contó con la actuación de famosos actores en los papeles principales: Ben Affleck es el protagonista Michael Jennings, Uma Thurman es Rachael -mujer de la que se enamora Jennings durante los años de trabajo y que luego no recuerda, y que no aparece en el relato de Dick $^{2}-$, y Aaron Eckhart es James Rethrick, el malvado presidente de la compañía Allcom. También forman parte del reparto reconocidos intérpretes como Paul Giamatti o Michael C. Hall.

Aunque en el texto de Dick la acción transcurre en un futuro lejano, en la adaptación se escoge el presente pero con avances tecnológicos, como los sistemas de borrado de memoria, que apuntan a un periodo temporal más desarrollado. También cambia la ciudad, ya que en el cuento el personaje se mueve entre Nueva York y Stuartsville (Iowa), mientras que en la adaptación el emplazamiento urbano es Seattle.

No son los únicos cambios, ya que en el cuento el protagonista se ve atrapado en un sistema en el que los derechos individuales han sido prácticamente abolidos y solo mantienen sus derechos las empresas. Jennings se encuentra acorralado por dos gigantes que ostentan todo el poder: por un lado, la Policía de Seguridad, es decir, el Gobierno; por otro, Construcciones Rethrick. "Un individuo ya no tiene ningún lugar en el que refugiarse, nadie en quien confiar, nadie que le ayude. Está atrapado entre dos fuerzas despiadadas, la política y los poderes económicos" (Dick 2005: 356), se queja el personaje. En la película, cuyo marco temporal son los primeros años del siglo

\footnotetext{
2 Aunque en el cuento de Dick sí aparece una mujer, Kelly, el protagonista no mantiene con esta una relación durante los años que dura el trabajo y de los que borran todos los recuerdos. Jennings le solicita ayuda para guardar las fotografías que consigue hacer del rastreador temporal, pero ella al final lo traiciona porque resulta ser la hija de Rethrick.
} 
XXI, el Gobierno no es mostrado como un enemigo, e incluso los dos agentes del FBI, a pesar de que Jennings huye, entienden su situación y lo protegen para que el Fiscal General Brown no continúe la persecución.

La variación temporal de la adaptación tiene efectos evidentes en la configuración de la ciudad, sobre todo en lo que se refiere a los avances en los medios de transporte: si en el relato Jennings viaja en cruceros privados aéreos conducidos por robots y sube a bordo de cohetes interciudades, en la película son vehículos actuales como el autobús, la moto o el metro los que cobran protagonismo.

No obstante, espacios como la estación, que ya aparecía en el cuento, tienen una especial relevancia al ser utilizados como lugares de acción y violencia. También los vehículos ya citados son usados al estilo de una película de acción, género en el que es especialista John Woo, que ya había dirigido títulos tan conocidos como Cara a cara (1997) o Misión Imposible II (2000). Por tanto, el director chino va a explotar las características trepidantes y violentas que contiene la obra de Dick para fomentar un film encuadrado claramente en el género de acción y en el que los elementos de ciencia ficción no se desarrollan plenamente, de tal manera que solo sirven como pretexto.

Así, cuando Jennings huye del FBI entra en la estación de autobuses y sube a uno, mientras los agentes lo pierden de vista. La estación vuelve a ser protagonista cuando Jennings se reúne con Shorty, su amigo: la elección de un espacio público, lleno de personas y mobiliario urbano, es una recurrencia del género, ya que dota de gran espectacularidad los destrozos causados por disparos y explosiones. En efecto, los asesinos de Allcom que han seguido a Jennings disparan sin éxito al ingeniero y solo aciertan a destruir distintos puestos móviles de bollería, de herramientas de cocina, de flores, de libros, etc., y los típicos escaparates de cristal que atraviesa el protagonista (figura 1 ). Todo ello se refuerza visualmente con tomas a cámara lenta y acústicamente con una banda sonora adecuada para generar tensión en el espectador. La huida lleva a Jennings a descender al espacio subterráneo del metro, donde se esconde en los pasillos oscuros cubiertos por gruesas tuberías, de una de las cuales, tras impactar en ella un disparo, comienza a brotar una densa humareda blanca. El protagonista llega a las vías del metro, en donde John Wolfe -la persona de confianza de Rethrickespera que muera atropellado, pero Jennings consigue que el tren frene a pocos centímetros de alcanzarlo manipulando el dispositivo de seguridad. 


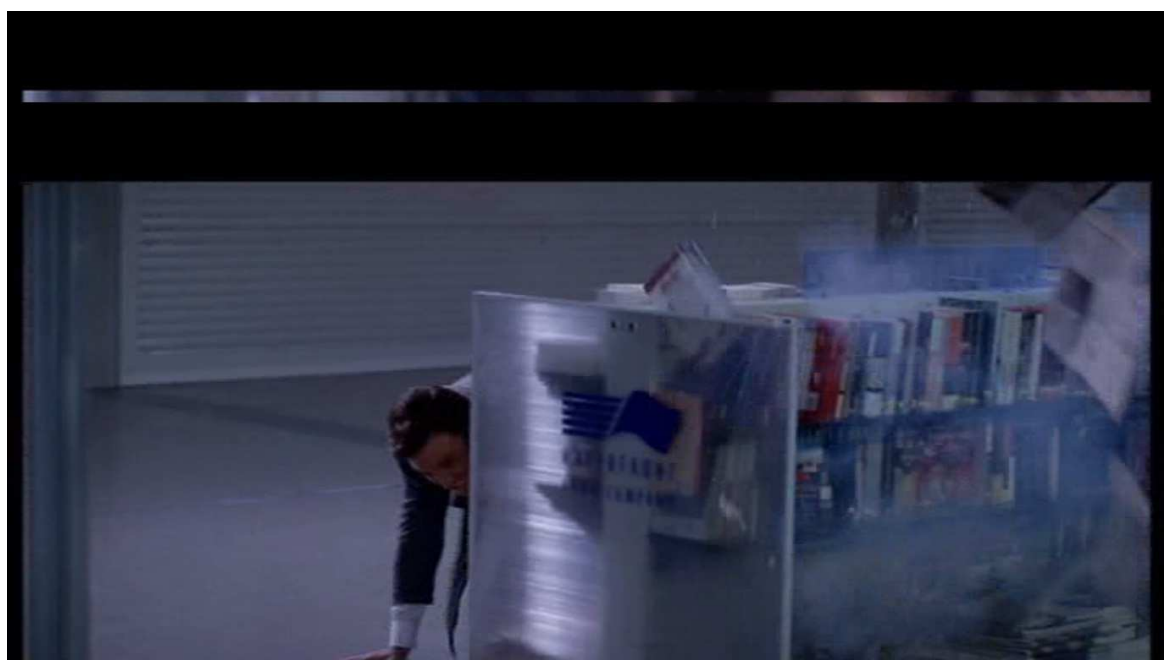

Figura 1. Tiroteo en la estación.

Como en cualquier película de acción que se precie, también hay una persecución de vehículos, pues Jennings y Rachael huyen con una moto mientras los coches de los pistoleros de Allcom los siguen a escasa distancia. Tras dejar atrás las calles de la ciudad, el espacio escogido para la escena está configurado por un terreno lleno de grandes containers abiertos por los dos extremos y por los que se introduce el motorista, a modo de túnel. Durante todo el recorrido se suceden los tópicos de este tipo de escenas: giros bruscos, conducción en dirección prohibida, disparos, roturas de cristales, colisiones, explosiones, etc.

El espacio íntimo, privado y protector que constituye la casa tampoco está exento de violencia, ya que la de Rachael está vigilada por cámaras de Allcom que la controlan hasta en el cuarto de baño. Es el FBI quien entra en la de Jennings y lo reducen de forma violenta, por lo que a partir de entonces no podrá volver a ella y se tendrá que hospedar en un motel.

Tanto en el relato como en la película Jennings se ve obligado a volver a entrar en la sede de la empresa para la que trabajó, en el cuento para demostrar la existencia del rastreador temporal y en la adaptación para destruirlo. El edificio parece inexpugnable en el relato de Dick ${ }^{3}$ :

Era una colina desnuda de toda vegetación, nada crecía en sus laderas. Una alambrada electrificada, tras la que montaba guardia un centinela armado con casco y fusil, impedía el acceso a la cima.

Un enorme bloque de hormigón en forma de torre, sin puertas ni ventanas, se distinguía sobre la cumbre. El sol de la mañana

3 También se ha hecho recurrente en las películas de acción que el protagonista tenga que ir o, como ahora, volver a un espacio fuertemente vigilado y en el que corre serio peligro si es descubierto. Sucedía también en Desafío total, Infiltrado y Minority Report. 
arrancaba reflejos de la fila de cañones montados sobre el tejado. (Dick 2005: 343)

En la película, a Jennings le resulta mucho más fácil la entrada en el edificio, ya que Rethrick, que lo vigila, quiere que entre y arregle la máquina que le permite ver el futuro para luego poder matarlo. El desenlace de la adaptación tiene lugar en las dependencias de la empresa: en la sala en la que se encuentra el rastreador temporal, en los conductos de ventilación y en el invernadero en el que trabaja Rachael. Por supuesto, las escenas siguen los patrones del género de acción: peleas cuerpo a cuerpo, disparos, explosiones... A ello ayuda el espacio de trabajo de Rachael, que con su niebla fortalece la confusión de los perseguidores (figura 2 ). De manera poco verosímil, Jennings, que al fin y al cabo es solo un ingeniero, consigue acabar con cualquier enemigo que tenga a tiro, con unas insospechadas dotes para disparar con pistolas y metralletas.

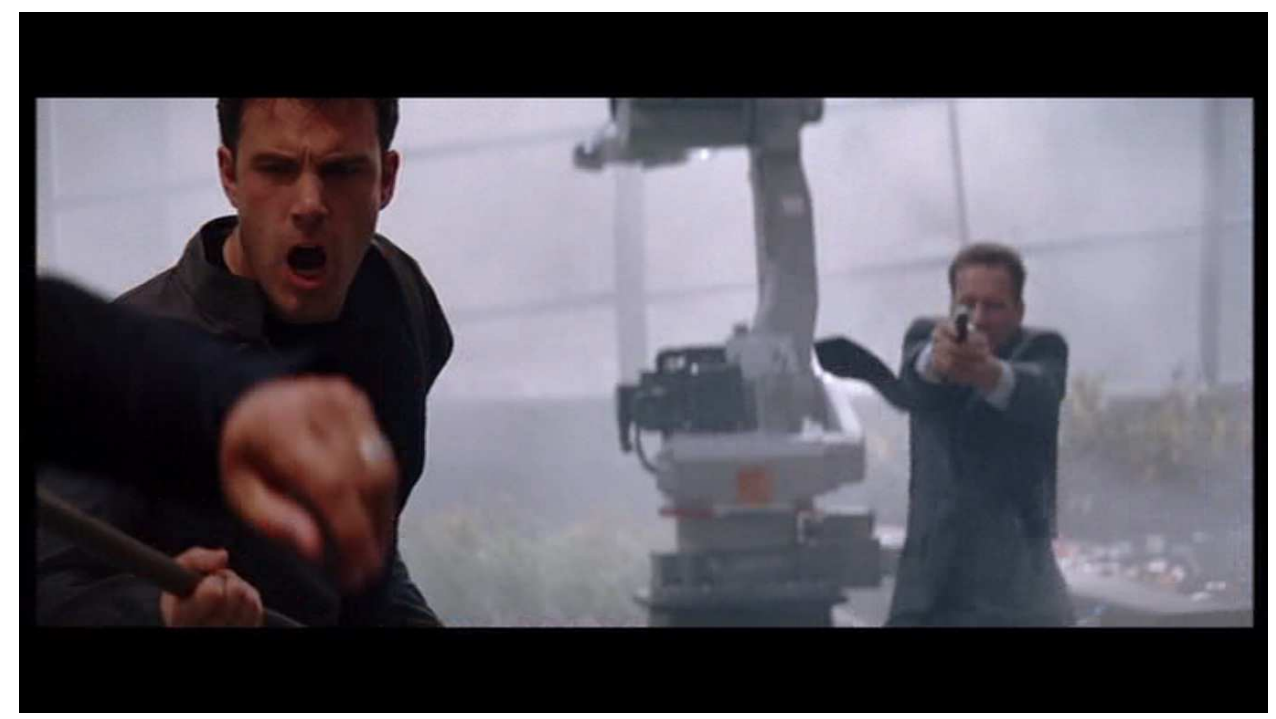

Figura 2. Escena final en el invernadero.

Paycheck es, en definitiva, una película de acción que convierte todos los espacios en decorados idóneos para escenas bélicas. Se cumple de nuevo el final feliz y Jennings no solo salva su vida, a pesar de que la máquina mostraba su muerte ${ }^{4}$, sino que además salva al mundo entero, escapa junto a Rachael, con la que continuará su relación amorosa, y, por si fuera poco, gana la lotería con los

${ }^{4}$ Otro punto discordante con el relato, ya que en este no se trataba la muerte del protagonista. Pero es más interesante todavía que recalquemos que mientras en los cuentos de Dick los sistemas de predicción del futuro son infalibles y se cumple la profecía, tanto en este relato como en "El informe de la minoría", en las películas adaptadas de estos textos se niega esta predestinación, fruto del interés actual en enfatizar que cada individuo es dueño de su futuro y negar el determinismo. 
números que había visto en la máquina y había jugado antes de su borrado de memoria. La película, que se ajusta a los patrones de una cinta de marcado carácter comercial, no fue del agrado de la crítica y tampoco obtuvo el éxito esperado en taquilla, ya que el margen de beneficios se situó por debajo del previsto.

\subsection{Una mirada a la oscuridad (1977) / A Scanner Darkly (2006)}

Richard Linklater fue el encargado de llevar al cine una compleja novela de Dick que, al contrario que las demás obras literarias que fueron adaptadas, no contaba con elementos de acción que propiciaran el interés de la industria hollywoodiense. Linklater, exitoso director de películas como Antes del amanecer o Tape, contó con la producción ejecutiva de Steven Soderbergh y George Clooney, además de un espectacular reparto para tratarse de un film independiente: Keanu Reeves, Winona Ryder, Woody Harrelson y Robert Downey Jr.

La novela de Dick, que contiene elementos autobiográficos, muestra la situación del distópico condado de Orange en un futuro cercano, en 1994, con un aumento considerable en el consumo de droga o Muerte Lenta. Además de los efectos de las drogas, se explora la cuestión de la identidad de los personajes, en especial la del protagonista, el agente Fred, que realiza una misión infiltrado bajo el nombre de Bob Arctor. Bajo la personalidad de Arctor, el policía convive con otros jóvenes inmersos en la cultura de las drogas. El propio Arctor, para fortalecer su papel, participa en el consumo de Muerte Lenta, lo que va dañando progresivamente su cerebro hasta el punto de no poder disociar sus dos personalidades, lo que resulta todavía más peligroso cuando le ordenan, como agente Fred, vigilar a Arctor. Las drogas destrozan sus capacidades y Donna, su pareja, lo lleva a New Path, un centro de rehabilitación en el que es rebautizado como Bruce. La pérdida de identidad es, pues, total:

Bob Arctor pensó para sí, ¿Cuántos Bob Arctor hay? Un jodido y extraño pensamiento. Dos que se me ocurran, pensó. El que se llama Fred, que observa al otro, llamado Bob. La misma persona, ¿o no? ¿De verdad Fred y Bob son la misma persona? ¿Alguien lo sabe? Si alguien lo supiera debería ser yo, puesto que soy la única persona del mundo que sabe que Fred es Bob Arctor. Pero, pensó, ¿quién soy yo? ¿Cuál de ellos soy yo? (Dick 2006: 97)

La película es bastante fiel a la obra de Dick. Linklater utiliza la técnica de la rotoscopia, consistente en mostrar una imagen animada procedente de una imagen fílmica original, para incidir en el carácter difuso de la identidad de los personajes y poder representar el traje de combate de los agentes, compuesto por un mosaico de partes del 
cuerpo de distintas personas que cambian constantemente, para no revelar la apariencia real del policía (figura 3). Esta técnica la había empleado ya en Wakinglife, de 2002.

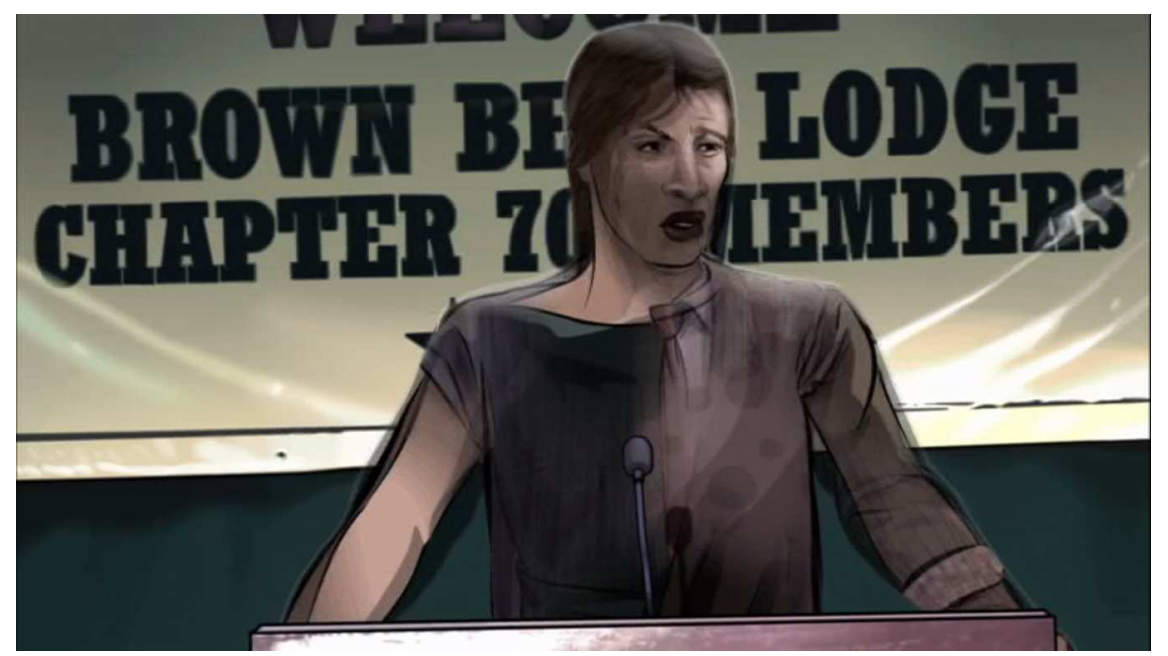

Figura 3. El agente Fred dando un discurso con el traje de combate.

La ciudad es insegura y las amenazas constantes. Hay una clara diferenciación entre las zonas de los ricos y las de los pobres, y los consumidores de la Muerte Lenta son despreciados y marginados por los poderosos. El peligro además es mayor desde la perspectiva de los drogadictos, ya que el consumo de la sustancia M causa en ellos una paranoia constante que les hace sentir perseguidos.

El efecto de las drogas motiva la ensoñación de nuevos espacios en los que estas puedan ser comerciadas legalmente, como imagina Charles Freck los escaparates del almacén Thrifty, aunque no sea más que un deseo que enseguida se frustra ante la contemplación de la realidad: "en el escaparate del Thrifty normalmente no había nada: peinas, botellas de aceite mineral, botes de desodorante en spray, siempre ese tipo de basura" (Dick 2006: 11).

El espacio doméstico es el más relevante en la obra de Dick y en la de Linklater: la casa pierde su carácter protector debido al miedo - provocado por la Muerte Lenta- que sienten Arctor, Barris y Luckman. Por temor a una conspiración, Barris deja la puerta abierta con una nota que así lo indica para que los invasores puedan ser grabados con el sistema de vigilancia que preparó. Al llegar a la casa, encuentran una colilla caliente, lo que da pie a descabelladas teorías, como que la policía escondió drogas para poder hacer un registro y detenerlos. El final de esta escena de claro carácter cómico -Luckman pretende atacar a los intrusos con un arco, pero no tiene flechas- se resuelve cuando aparece Donna, que resulta ser la que entró tras leer la nota (figura 4). 


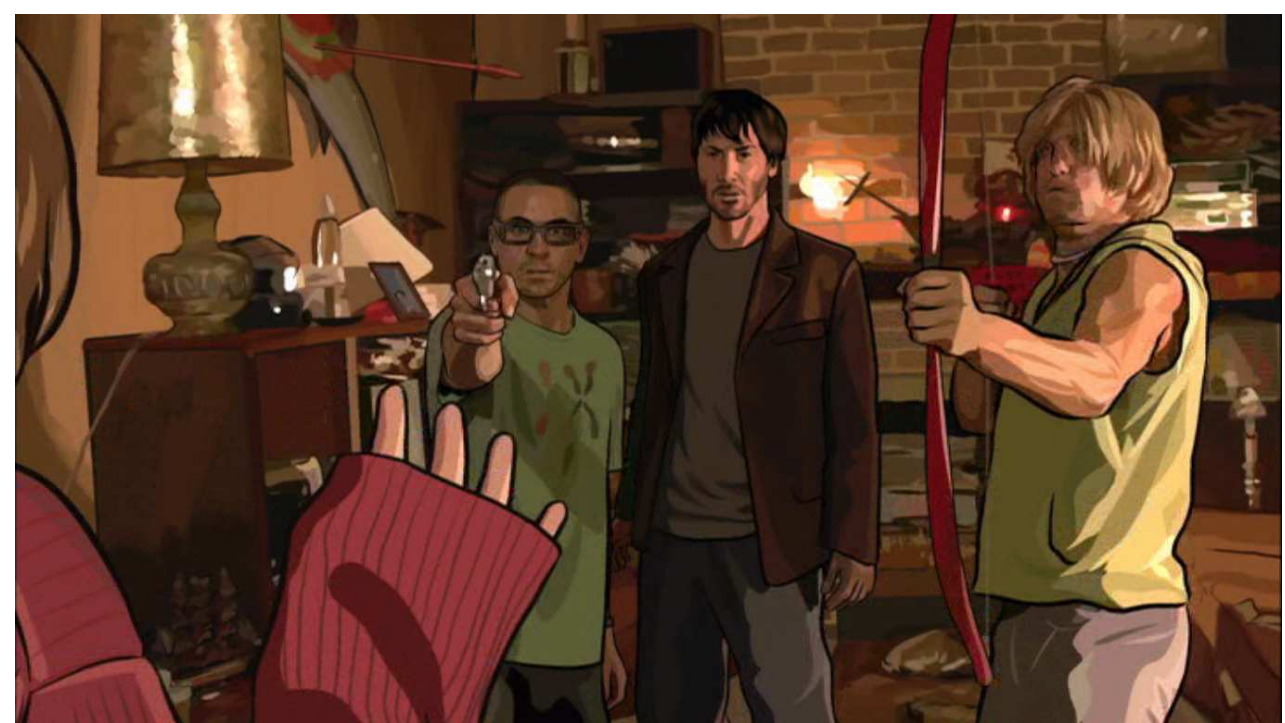

Figura 4. Los jóvenes descubren que Donna está en la casa.

Cuando a Fred le ordenan vigilar a Bob Arctor, es decir, a sí mismo, tienen que introducir en la casa holoescáners para grabar todo lo que allí ocurre. Arctor, por tanto, sabe que está siendo vigilado, y que todo lo que hace queda registrado y es analizado por Fred, aunque a medida que avanza la obra la disociación de identidades provoca que Fred no sea consciente de que es Arctor y viceversa. Es por ello que, una vez afectado su cerebro y disociadas sus identidades, va a la casa y, al observarla con ojos extraños, se fija en el patio descuidado y la basura rebosante y determina que "deberían quitársela [...] y darle un uso mejor; la casa lo está deseando" (Dick 2006: 181). La casa se vuelve asfixiante, cohíbe al protagonista que debe interpretar, como un actor, que no están los holoescáners para no ser descubierto.

Con el avance de la investigación y por el efecto de la sustancia $\mathrm{M}$, el cerebro de Arctor va quedando cada vez más deteriorado. Por ello es internado en New Path, un centro de desintoxicación en el que tratan duramente a los pacientes. Donna, que resulta ser también una agente oficial secreta, es la encargada de llevarlo, y más tarde, en una conversación con otro agente, señala que Arctor, rebautizado como Bruce en New Path, está infiltrado allí sin su conocimiento para obtener información del centro, del que se sospecha que es el principal productor de la droga.

En New Path, Bruce acude a sesiones traumáticas como "el Juego", en la que el resto de internos lo insultan. Debido a sus pocos progresos, es destinado al medio rural a trabajar en los cultivos de New Path en Napa Valley. Allí descubre la flor de la que se extrae la sustancia $M$, aunque no es consciente de ello. Sin embargo, guarda una flor para el regreso a casa, por lo que la historia termina con un halo de esperanza: tiene la prueba de los negocios a los que se dedica New Path. 
La novela de Dick, con elementos de ciencia ficción, explora las consecuencias del consumo de drogas y la marginación con las que son tratados los drogadictos. En la "Nota del autor" al final del libro, que también recoge parcialmente Linklater, Dick denuncia que esas personas "sufrieron un castigo demasiado severo por lo que hicieron" (Dick 2006: 269) y dedica su novela a amigos que por el consumo de drogas fallecieron o tuvieron enfermedades permanentes, como el propio autor, con "lesiones pancreáticas permanentes" (Dick 2006: 271).

La adaptación de Linklater es muy fiel a la novela, con una magnífica estética de animación sustentada en buenas actuaciones. El riesgo que asume el director ha sido merecedor de muy buenas críticas, como que es "la mejor adaptación de la obra de Philip K. Dick -en el sentido que es la que mejor refleja el mundo creativo de dicho autor-" (Villarrubia Jiménez-Momediano 2010: 277). El espacio urbano, como en la novela, se representa a través de la visión subjetiva de los consumidores de droga, con elementos psicóticos como la manía persecutoria que tergiversan la ciudad y la convierten en un lugar amenazante.

\section{8. "El hombre dorado" (1954) / Next (2007)}

Tras A Scanner Darkly, Lee Tamahori fue el encargado de volver a llevar a la gran pantalla una narración de Dick, en este caso "El hombre dorado". De nuevo, el director escogido había filmado películas de acción como Muere otro día, de la saga James Bond, o $X X X$ 2: Estado de emergencia. El actor principal es Nicolas Cage, también productor, y las actrices Julianne Moore y Jessica Biel.

En este caso, la adaptación del relato se limita a rescatar la anécdota o la particularidad del cuento de Dick para configurarla de manera completamente distinta. En "El hombre dorado" se narra la situación tras un episodio postapocalíptico en el que surge una serie de mutaciones en diversas personas. La Policía Civil Gubernativa busca a todos los mutantes para encerrarlos y analizar sus nuevos poderes. Uno de los agentes va a Walnut Creek, en donde encuentra al hombre dorado -llamado así por el color de su piel-, que posee el poder de contemplar con antelación lo que sucederá en los dos próximos minutos y actuar para modificar las consecuencias. Consiguen detenerlo y llevarlo a unos laboratorios para estudiarlo, pero además de su habilidad para predecir el futuro posee otra con la que es capaz de seducir a las mujeres. Así logra salir del edificio y huir.

Como este último punto no es políticamente correcto, es eliminado de la película, además de la relación de los personajes, el contexto postapocalíptico y la aparición de mutantes, la detención para su análisis, etc. La adaptación solo mantiene el poder del personaje y la búsqueda que llevan a cabo los agentes, en un marco 
temporal actual. La película tuvo cierto éxito de público, a pesar de que los beneficios tras la recaudación en taquilla fueron menores que los de Paycheck, pero fue muy poco valorada por la crítica.

El espacio urbano es poco tratado en el relato, ya que no es una narración en la que cobre especial protagonismo. El agente pregunta en una cafetería si alguien conoce mutantes en la zona, y una información lo lleva a la granja de los Johnson, donde capturan a Cris, el hombre dorado. De allí, lo llevan a una sala desierta, "cuatro paredes desnudas, el techo y el suelo" (Dick 2007: 58), de donde huye valiéndose de las estancias del aislado edificio en el que lo retienen.

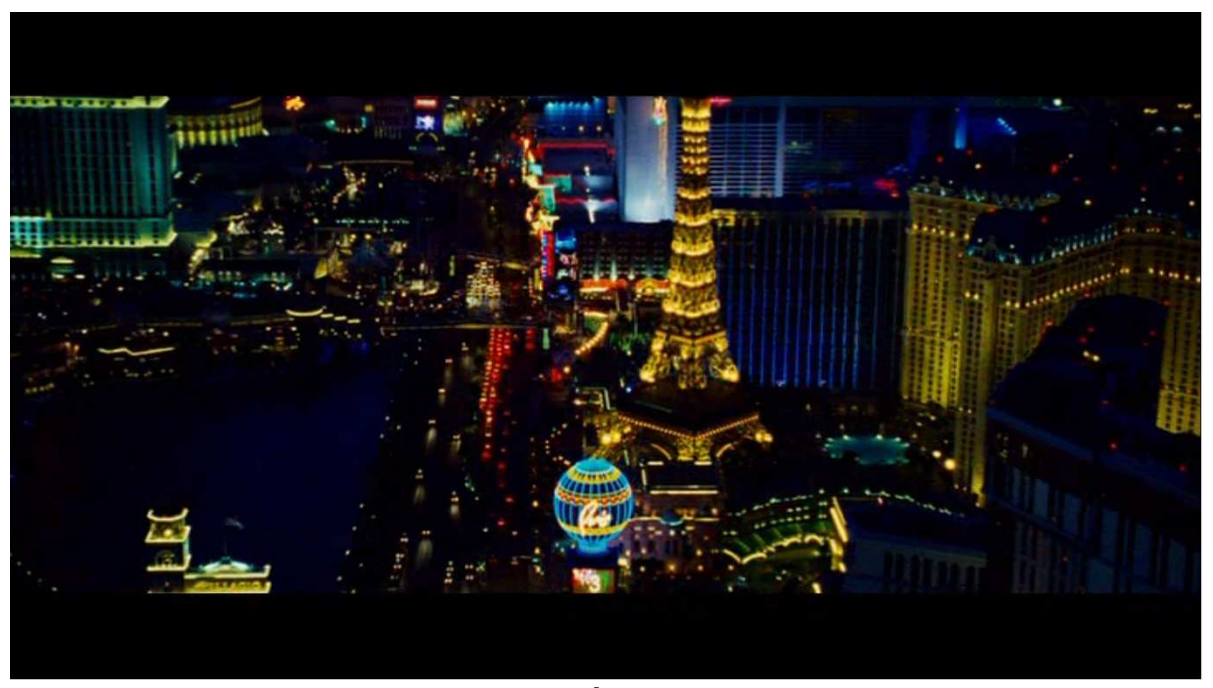

Figura 5. Vista aérea de Las Vegas.

La película, sin embargo, al estar ambientada en la época actual, utiliza un marco fácilmente reconocible. Así, el protagonista, Cris Johnson, trabaja como mago en Las Vegas. La ciudad del pecado, que es introducida con una visión de los hoteles, casinos y rascacielos al ritmo de una canción de Elvis Presley, es el lugar perfecto para que Johnson pueda ganarse la vida con su poder y pasar totalmente desapercibido (figura 5). El espectáculo y el juego son los medios de supervivencia en una ciudad superficial en la que todo es posible, ya que como dice Johnson, "lo que pasa en Las Vegas, se queda en Las Vegas". La ciudad, mitificada en el cine como espacio para el juego y la fiesta, tiene un papel fundamental en el principio de la película, en la que se explica y demuestra al espectador el particular poder de Johnson. Tras una función suya, va a una sala de juegos, en la que gana dinero jugando a las máquinas tragaperras y al póker. Los agentes de seguridad del casino se percatan de que siempre gana y deciden ir a interrogarlo, pero Johnson se anticipa y decide huir. Sin embargo, cuando va a recoger el dinero se topa con un atracador, que en el futuro que contempla el 
protagonista matará a dos personas. Para evitarlo, lo empuja, lo desarma y huye ante la presencia de los vigilantes, de los que se esconde valiéndose de su poder y del laberinto formado por las filas de máquinas tragaperras (figura 6). Johnson logra salir del casino, robar un coche y continuar la huida, esta vez de la policía, por las carreteras, en donde logra evitar la colisión con un tren y escapar definitivamente.

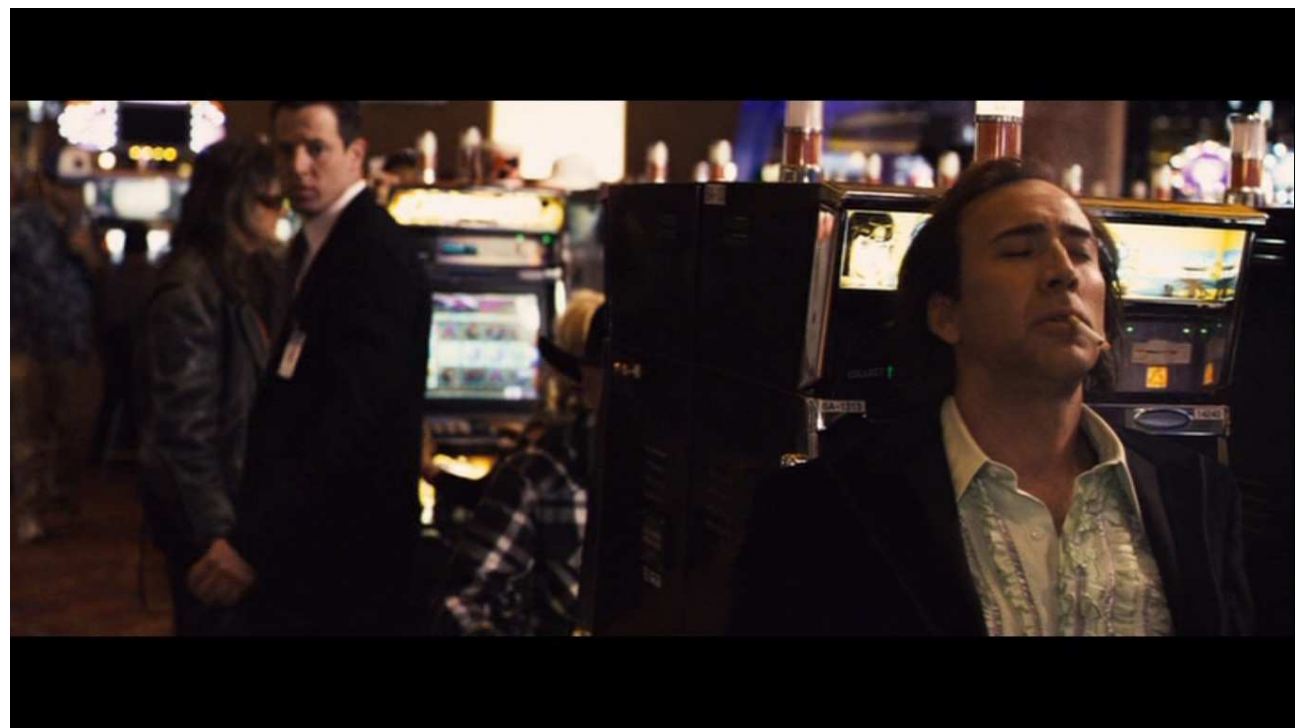

Figura 6. Johnson huye entre las hileras de máquinas tragaperras.

Unos agentes antiterroristas lo siguen, conocedores de su poder, para descubrir los planes de un grupo que pretende poner una bomba nuclear en los Estados Unidos. Por otro lado, Johnson había tenido la visión de una mujer - no puede faltar la trama amorosa-, que encontraba en un restaurante. Así, el protagonista debe huir de los agentes e intentar enamorar a la mujer de sus sueños, a la que encuentra. Con ella, Elizabeth Cooper (Jessica Biel), va a Flagstaff a una comunidad de nativos americanos, pero no pueden continuar el viaje y duermen en un motel, en el que tendrán una relación sexual.

Al día siguiente, la agente Callie Ferris (Julianne Moore) trata de convencer a Elizabeth de la necesidad de detener a Johnson. Elizabeth confía en Johnson y lo ayuda a escapar, dando lugar a una escena de acción en un precipicio. Sin embargo, el protagonista es capturado por Ferris y su amada secuestrada por los terroristas. A Johnson lo llevan a una prisión, pero como sucedía en Paycheck, su capacidad de conocer el futuro le permite enfrentarse a los agentes y salir de ella.

Los Ángeles aparece entonces como el escenario de los enfrentamientos entre FBI y terroristas, sobre todo el puerto, en el que sucede el desenlace: las naves industriales y los containers son el decorado del tiroteo entre los criminales y los agentes, que continúa en un barco que proporciona elementos característicos de este tipo de 
películas, como la oscuridad y los pasillos laberínticos a distinto nivel, que junto con la banda sonora generan tensión.

Al final, aunque rescatan a Elizabeth, la bomba nuclear estalla, pero todo resulta ser una visión del futuro de Johnson, que lo ve al amanecer en el hotel. Para evitar la explosión, decide despedirse de Elizabeth y colaborar con Ferris. El final es abierto y Johnson cumple con su deber de buen ciudadano y colabora con las autoridades para intentar capturar a los terroristas.

Este final deja una cierta decepción en el espectador, ya que solo ha visto un futuro posible y no el real. Además, tampoco aclara por qué, si su poder es ver solo dos minutos de su futuro, consigue anticiparse tanto tiempo. Estamos de nuevo ante la utilización de las narraciones de Dick para crear una película de acción: el espacio urbano es el escenario de persecuciones, tiroteos y explosiones. El paisaje natural de Flagstaff, aunque presentado en un principio como lugar idílico en el que se desarrolla el romance de los protagonistas, también se vuelve peligroso cuando tienen que comenzar la huida. Uno de los pocos hallazgos interesantes de la adaptación es la elección de Las Vegas como ciudad en la que trabaja Johnson, el espacio ideal para pasar desapercibido entre tanta excentricidad, que también aparece como espacio hostil del que el protagonista debe huir.

\section{9. "La segunda variedad" (1953) / Asesinos cibernéticos 2 (Screamers: TheHunting) (2009)}

Asesinos cibernéticos 2 es un enigma en la producción cinematográfica, pues cabe plantearse qué propósito había en rodar una secuela de una película que cosechó tan poco éxito. Como se preveía, esta continuación ni siquiera se estrenó en cines, sino que se distribuyó directamente para su comercialización en DVD. Sheldon Wilson fue el encargado de dirigirla con actores desconocidos como Gina Holden, Jana Pallaske y Lance Henriksen. Wilson, experimentado en trabajos de terror, impregna la película de escenas gore, con partes del cuerpo cercenadas y sangre a borbotones.

Esta cinta desarrolla los preceptos del cuento de Dick, con la amenaza de los garfios - un arma autónoma que trata de asesinar a los humanos-, y continúa la trama de la primera película de la saga. En una nave espacial, los personajes ven el vídeo que les informa de la guerra en Sirius 6B y de la creación de los garfios. Hendricksson, el único superviviente, se suicidó haciendo explotar su nave al penetrar en la atmósfera terrestre, pero trece años después se recibe una petición de ayuda: los tripulantes de la nave deben rescatar a la persona que permanece en el planeta en un plazo de seis días, ya que entonces impactará un meteorito solar. En la misión viaja Victoria Bronte, la hija de Hendricksson, al que nunca conoció. 
Los espacios representados en la película demuestran la escasez de presupuesto y de creatividad con la que contó la producción. Además del interior de la nave, poco explotada, aparecen cuatro espacios muy similares en el planeta desierto: el búnker en el que se fabricaron los screamers, la cueva en la que viven los supervivientes, la mina en la que duermen la última noche y las ruinas del complejo. Todos son oscuros, de aspecto primitivo, sucios, fruto del abandono de tantos años. La tétrica atmósfera se completa con anchas tuberías. La fábrica de screamers también ofrece un aspecto desolador, con hileras de máquinas desconectadas llenas de telarañas. Solo en el complejo encontramos restos de tecnología en uso, en el habitáculo en el que todavía vive Eugene Orsow, cuya tecnología e iluminación contrastan con el resto de espacios (figura 7).

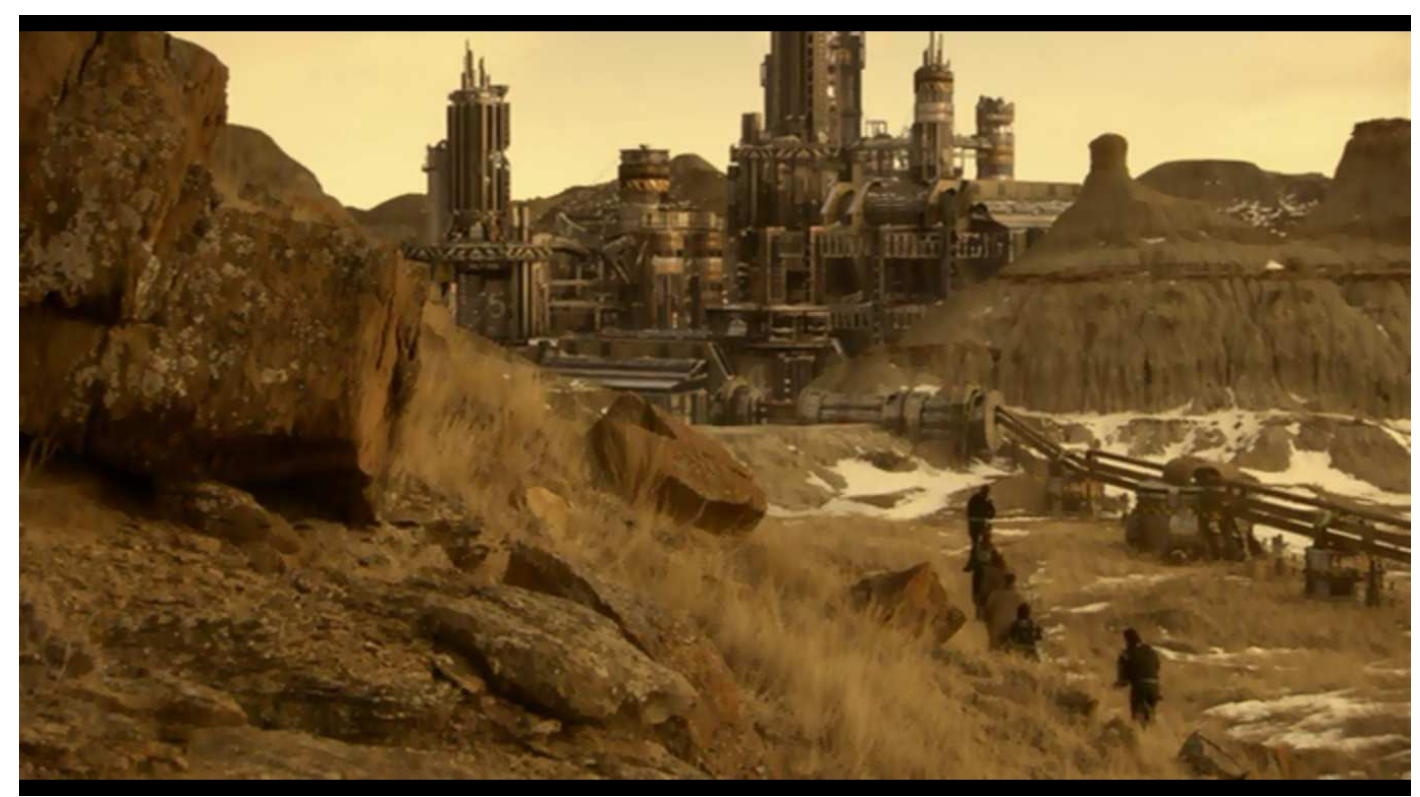

Figura 7. Las ruinas del complejo en el que vive Orsow.

La intención de la ambientación de estos lugares es clara: generar tensión con la oscuridad para propiciar los sobresaltos característicos de una película de terror, también con elementos propios del género de acción, como la explosión que destruye las cuevas en las que vivían los supervivientes. El decorado es, por tanto, exiguo, posiblemente auspiciado por el bajo presupuesto de la cinta, que también se manifiesta en el vestuario poco elaborado y en los instrumentos de atrezzo.

La película sigue el patrón de la primera entrega: desconfianza entre los personajes, que no saben quién puede ser un screamer. Como en la adaptación de 1995, se añade una trama amorosa, en este caso entre la hija de Hendricksson y el superviviente, y como en aquella, al final resulta que este es un screamer y no solo parte en la 
nave con ella, sino que además la deja embarazada de un híbrido entre humano y screamer.

Como se puede deducir fácilmente, la película prácticamente no gozó de atención por parte de la crítica, ni siquiera de los espectadores. Se trata de una secuela que no aporta nada, ya que repite y empeora la primera entrega, y es sin duda alguna la peor adaptación de un relato de Dick.

\subsection{0. "Equipo de ajuste" (1954) / Destino oculto (The Adjustment Bureau) (2011)}

La última película estrenada hasta el momento basada en una obra de Dick fue dirigida por George Nolfi. Destino oculto fue su primera película como director, en la que también se ocupó del guión. Antes, Nolfi había sido guionista de Ocean's Twelve y coguionista de El ultimátum de Bourne, entre otras. Los protagonistas de la película fueron Matt Damon y Emily Blunt.

El relato de Dick presenta paralelamente la labor de un equipo de ajuste y un día cotidiano de Ed Fletcher. El equipo de ajuste se encarga de velar para que se den unas circunstancias necesarias para poder desenergizar a algunas personas y dotarlas de las cualidades que se requieran. En este caso, pretenden modificar a Douglas, jefe de Fletcher, para que adquiera una zona forestal en el oeste de Canadá en la que, al iniciar las obras para edificar, encontrarán restos antropológicos que reunirán a los científicos de todo el mundo. Sin embargo, el encargado de asegurarse de que Fletcher llega a la oficina antes de la desenergización, que es un perro parlante, se queda dormido y, por lo tanto, Fletcher llega tarde al trabajo. Lo que descubre es una inquietante niebla espesa, y tanto el edificio como las personas parecen construidos de ceniza:

La escalera cedió bajo sus pies, que se hundieron como si caminara sobre arena o sobre un material frágil y podrido que se rompiera bajo su peso. [...]

Ed se dirigió hacia el hombre. Alargó la mano y le tocó.

El hombre se desplomó lentamente, convertido en un montón de ceniza gris. Polvo. Partículas. Las dos mujeres se desintegraron cuando las tocó. En silencio. No hicieron el menor ruido al desmenuzarse. (Dick 2011: 363)

En la película el protagonista es David Norris, candidato a senador por el Estado de Nueva York. Tras perder las elecciones, conoce por casualidad a una mujer de la que se enamora. Norris acepta un puesto de trabajo en una gran empresa, y el día en el que 
debe defender un importante proyecto el equipo de ajuste ${ }^{5}$ intenta que llegue tarde, cuando su trabajo haya terminado. Sin embargo, el miembro encargado, esta vez una persona, se queda dormido y Norris viaja en autobús. Allí vuelve a ver a la mujer y apunta su número de teléfono. Al llegar al trabajo todas las personas están paralizadas, y Norris no se da cuenta de ello hasta que llega a la sala de reuniones, en la que ve cómo el equipo de ajuste está reprogramando a sus compañeros.

La escena presenta el edificio y los personajes de manera realista, por lo que se pierde un elemento que podría haber resultado mucho más destacable, como lo hubiera sido configurar el espacio y las personas como estructuras de ceniza o arena, lo que permite realizar diversas lecturas sobre el proceso.

En cambio, la película desarrolla más la trama: en el relato Fletcher huía y se lo contaba a su mujer, quien no le creía, para finalmente llegar a un trato con el equipo de ajuste por el que le dejarían tranquilo si no se lo cuenta a nadie; mientras que en la adaptación el encuentro con Elise da lugar a un argumento más complejo, ya que los hombres del sombrero, para hacer cumplir el plan del Director ${ }^{6}$, intenta evitar el romance, pero el protagonista se rebela. Estamos, pues, ante una película romántica ${ }^{7}$.

La ciudad representada en esta película es Nueva York, entre el 2006 y el 2010, por lo que tiene un marcado carácter realista. No obstante, Nolfi utiliza un ingenioso recurso para mostrar el medio de transporte de los miembros del equipo de ajuste: abren la puerta de un edificio y aparecen en otro completamente distinto. Para seguir a Norris utilizan las puertas para ir de un armario a Chinatown, de allí a una calle, para aparecer por la Robert Miller Gallery. La complejidad de conexiones entre las puertas en Nueva York dificulta el trabajo del equipo y uno de los miembros exclama: "no soporto esta ciudad".

Nueva York es el escenario por antonomasia del cine estadounidense, que ha creado un imaginario a través de los espacios urbanos y lo ha difundido a todo el mundo. Destino oculto no innova, salvo el ya mencionado transporte a través de las puertas, en la representación de la ciudad, y por ello utiliza indistintamente lugares ya comunes por la reiteración con la que aparecen en las obras audiovisuales del país norteamericano. Así, por ejemplo, Norris ofrece

${ }^{5}$ Los miembros del equipo de ajuste se caracterizan por ser hombres vestidos con traje y corbata y llevar sombrero.

${ }^{6}$ El Director es trasunto del dios único, que configura el destino de la humanidad. El equipo de ajuste, por tanto, viene a ser un grupo de ángeles, tal y como señala Norris.

7 Si bien prácticamente todas las películas adaptadas han tenido una subtrama romántica, el género imperante ha sido el de acción. Con Destino oculto se amplían las posibilidades de adaptación de los textos de Dick. 
su discurso junto al río -al lado del puente de Brooklyn- y en la orilla de enfrente, en el muelle 17, Elise debería ensayar con su compañía de danza. Finalmente, y debido a las maquinaciones del equipo de ajuste, Elise trabaja en el emblemático edificio de la compañía de ballet contemporáneo Cedar Lake. Las oficinas, cafeterías y discotecas corroboran el aspecto realista de los espacios de la película, tan solo matizados por el lugar en el que los hombres del sombrero lo retienen, una especie de nave industrial desierta con columnas y mucha iluminación (figura 8 ).

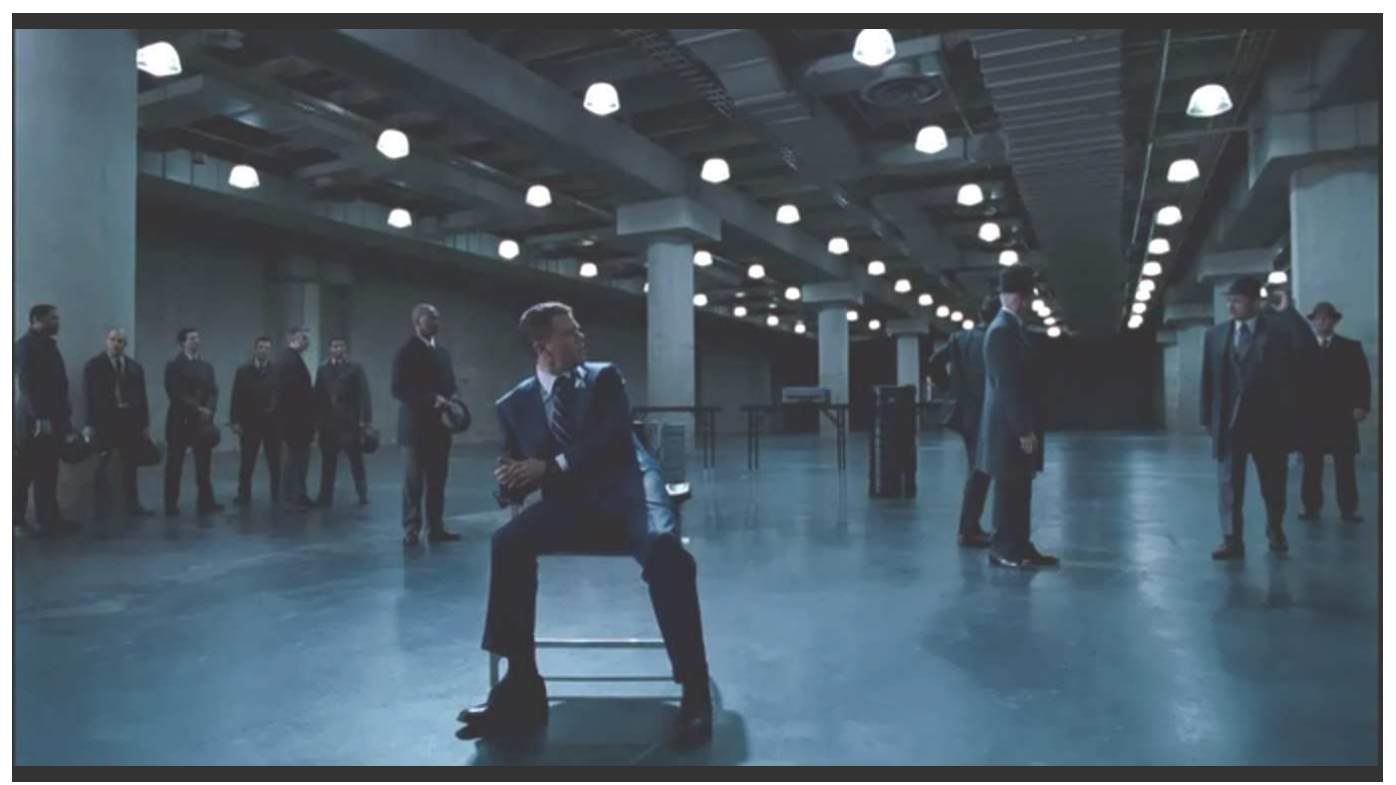

Figura 8. El equipo de ajuste con David Norris.

Los espacios ya tópicos de Nueva York en el cine aparecen en las escenas finales, cuando Norris, dispuesto a contravenir el plan trazado, utiliza las puertas con la ayuda de uno de los "ángeles" para impedir la boda de Elise y huir con ella. Como cuando se conocieron, los protagonistas se encuentran en unos baños públicos ${ }^{8}$, pero a través de las puertas van a parar al estadio de los New York Yankees, a los exteriores del MOMA y a la Estatua de la Libertad. La película termina con la pareja en el edificio en el que trabajan los miembros del equipo de ajuste, con la intención de hablar con el Director. Recorren pasillos, una estancia parecida a una biblioteca y diversos despachos $^{9}$ para terminar en la azotea de un rascacielos desde la que

${ }^{8}$ Este peculiar espacio, en principio destinado a la privacidad, se convierte en un lugar propicio para el romance debido, en el primer encuentro, a un error de Elise, que se equivoca al entrar en el baño de caballeros, en el que coincide con Norris; y en el desenlace, al atrevimiento del protagonista, que entra para impedir la boda en el baño de mujeres en el que ella, nerviosa, se prepara para el acto.

9 Resulta llamativa la configuración del lugar de trabajo de estos "ángeles": un espacio propio de cualquier administración en el centro de Manhattan. Hasta lo divino aparece teñido de burocracia. 
se divisa toda la ciudad, con espacios tan reconocibles como el Central Park o el Empire State (figura 9).

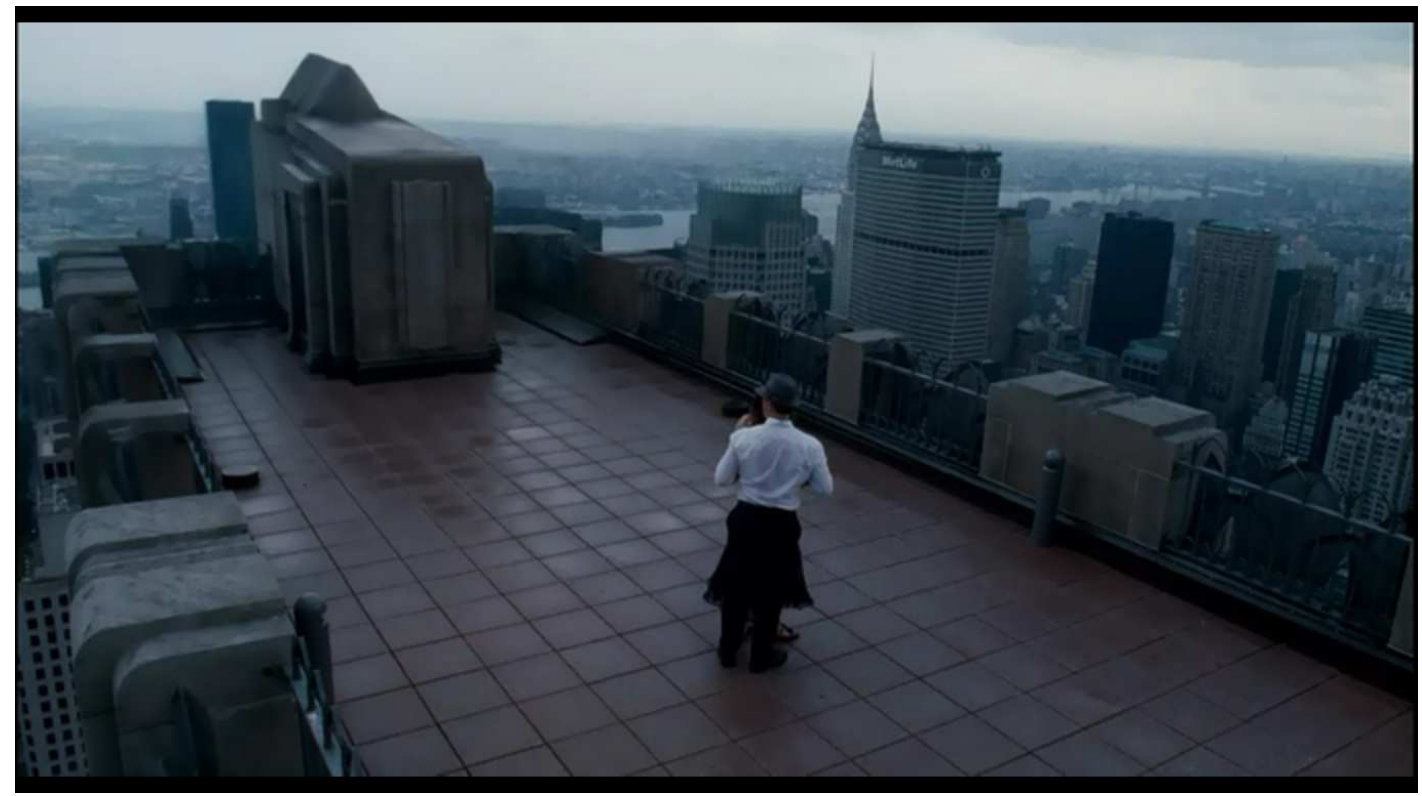

Figura 9. Escena final en la azotea.

Como sucedía en Minority Report o Paycheck, el destino no se cumple y el protagonista vence. Norris logra que el libre albedrío triunfe sobre el determinismo y la pareja puede comenzar su relación amorosa en este nuevo final feliz, otro más en las adaptaciones de Dick.

Se trata, por tanto, de una película claramente enmarcada en el género romántico que sigue un esquema muy similar al de este tipo de producciones hollywoodienses. Al no contar con costosos efectos especiales, el presupuesto del film no fue especialmente alto (en torno a unos 50 millones de dólares) y la recaudación fue considerablemente superior, una cifra que casi triplica el presupuesto.

No obstante, en lo relacionado a la representación del espacio, la película no propone un enfoque novedoso y pierde la oportunidad de explotar la trama de ciencia ficción con la construcción de nuevos lugares. La visión que se ofrece de Nueva York presenta las calles y los edificios que el cine estadounidense se ha encargado de inmortalizar en infinitud de películas, por lo que el acercamiento de Nolfi resulta tópico.

\section{Las películas que vendrán}

En el momento de terminar este artículo, se celebra el 30 aniversario del estreno de Blade Runner y se especula con la posibilidad de que Ridley Scott dirija una segunda parte. Además, en verano de 2012 está programado el estreno de un remake de Desafío total, que llevará el mismo título original: Total Recall. Colin Farrell será el 
protagonista de una película que contará con otros rostros famosos como Ethan Hawke, Kate Beckinsale o Jessica Biel. El director será Len Wiseman, esposo de Beckinsale y experimentado en el género de acción, ya que dirigió las dos primeras entregas de la saga Underworld y La Jungla 4. Tras el estreno del tráiler en abril de 2012, lo poco que permite ver son escenas de acción en una ciudad futurista en la que los coches circulan por el aire.

Otras novelas que también se rumorea que se adaptarán pronto a la gran pantalla son Ubik, Fluyan mis lágrimas, dijo el policía y El hombre en el castillo, si bien esta última podría dar lugar a una miniserie para la televisión. El relato "El rey de los elfos" parece haber interesado a los estudios de Walt Disney, que estarían preparando una película de animación que llevaría el mismo título.

Independientemente de que estos proyectos se lleven finalmente a cabo o no, lo que queda de manifiesto es el interés de productores y directores en los textos de Dick, que poseen una gran cantidad de temas y elementos que ofrecen muchas posibilidades de desarrollo en el cine.

\section{A modo de conclusión}

Tras el análisis de estas diez películas, queda demostrado claramente el interés de la industria cinematográfica en adaptar los textos de Philip K. Dick. Desde el tardío culto a Blade Runner y el éxito de Desafío total, los productores vieron en la obra del autor estadounidense una magnífica materia prima sobre la que edificar sus proyectos, hasta el punto de que el nombre del escritor -o, por lo menos, la referencia como autor de la obra que inspiró Blade Runner y posteriormente Minority Report- sirve de reclamo publicitario. Si no, resulta difícil encontrar explicación al interés de los productores de Next y Destino oculto en atribuir la película a la adaptación de un relato de Dick, ya que ambas tan solo mantienen una característica del personaje o la anécdota de la historia y las desarrollan con absoluta libertad, por lo que la deuda contraída con el autor es más bien escasa.

Debemos incidir una vez más en el origen, la difusión y el fin de esas películas, ya que comprender estos aspectos es fundamental para entender este tipo de creaciones. En el complejo negocio cinematográfico, cualquier proyecto tiene que pasar por un gran número de filtros que avalen la rentabilidad del mismo. En efecto, la rentabilidad es el principal factor que motiva a los productores a llevar a cabo el rodaje y la posterior comercialización de una película, y por ello "muchas de las adaptaciones al cine que se realizan de obras de ciencia ficción están proyectadas desde Hollywood para un mercado amplio en todo el mundo, por lo que normalmente imperan las cuestiones comerciales y no la pretensión de crear una buena obra artística" (Rivero Grandoso 2011: 284). El concepto de arte está 
irremediablemente subyugado a la recaudación en taquilla y por ello se utilizan ciertos tópicos para tratar de agradar a un público masivo, entre ellos el del final feliz, pues hasta en Blade Runner, como ya comentamos, Ridley Scott tuvo que someterse a modificar el final en la versión que se estrenó en 1982.

Debido a la imperiosa necesidad de obtener beneficios, las obras de Dick se convierten en la gran pantalla en productos de género: "más que ficciones de inusitada profundidad e imaginación, el lugar común sobre los textos de Dick es que son combustible para películas de acción" (Chimal 2005: 100). En efecto, la mayoría de las películas se adscriben al género de acción, caracterizado por un presupuesto elevado pero unos beneficios también altos.

El papel protagonista suele ser interpretado por una estrella de Hollywood que sirve de reclamo para el gran público, como lo han sido Harrison Ford, Arnold Schwarzenegger, Tom Cruise, Ben Affleck, Nicolas Cage o Matt Damon. Las características del personaje son, con distintos matices, las de un héroe:

[...] el cine con más reclamo publicitario de los últimos años propugna, como nunca, el retorno a la galaxia de la acción por la acción, en un contexto urbano o futurista siempre empapado de gadgets tecnológicos, sobre el que los modernos héroes masculinos Bruce Willis, Mel Gibson, Nicolas Cage- ejecutan las más inverosímiles proezas gimnásticas gracias al túrmix de la inventiva digitalizante. (Bou y Pérez 2000: 97)

El protagonista se ve inmerso en un sinfín de luchas peligrosas, tanto cuerpo a cuerpo como con armas de fuego, a pesar de que en algunas películas se trate de un civil sin conocimiento aparente del manejo de armas. En otras, el personaje principal es un policía o miembro del ejército, lo que en buena medida sirve como justificación para las escenas de acción que se suceden casi sin descanso. El final feliz es la tónica habitual de las películas, en el que el héroe resulta triunfador y acaba románticamente con la chica. Aunque no es el momento de ahondar en ello por cuestiones de extensión y porque conllevaría que nos dispersáramos de los objetivos propuestos, sí que cabe al menos mencionar ciertas posiciones que pueden ser consideradas esquemáticas -e incluso machistas-, como que el protagonista sea siempre un hombre blanco heterosexual. La mujer queda relegada a un segundo plano para ser el motor de la subtrama amorosa; en algunos casos, debe ser rescatada por el héroe ${ }^{10}$. Si

10 Paradójicamente es Asesinos cibernéticos 2, la película adaptada menos exitosa, la única de las que hemos abordado cuyo personaje protagonista es una mujer, y además rescata al hombre del que se enamora, aunque al final se descubre que es un screamer. 
bien es cierto que en las obras adaptadas de Dick todos los personajes protagonistas son hombres, también lo es que varias de las películas han reelaborado libremente el argumento del escritor también en lo relacionado con los personajes-, por lo que no hubiera supuesto ningún inconveniente modificar el sexo del protagonista.

La película que más se aleja del género de acción y, sobre todo, de la configuración del héroe es $A$ Scanner Darkly, ya que "al no estar obligado al éxito de taquilla a cualquier precio, Linklater pudo correr el riesgo de reflejar toda la oscura ironía del original" (Villarrubia Jiménez-Momediano 2010: 278). Así puede escapar de los tópicos y del previsible final feliz, ya que entre sus objetivos no estaba el de agradar a un público amplio.

Más allá de la relevancia de la presión de la industria cinematográfica, lo que parece indudable es la trascendencia que han adquirido películas como Blade Runner, potenciadora de una estética urbana que ha influido en posteriores obras de ciencia ficción y videojuegos; Desafío total, hito del cine de acción que ha merecido un remake; o Minority Report, de sello Spielberg.

Resulta imposible intentar sistematizar los modelos urbanos que aparecen en la obra de Dick y en las posteriores adaptaciones, porque son casi tantos como las ciudades posibles en el género de ciencia ficción ${ }^{11}$. Las ciudades de Dick, presentadas todas en el futuro, están construidas con características distintas: espacios distópicos, alegóricos, utópicos, apocalípticos, postapocalípticos, etc. En algunas adaptaciones, como vimos, el tiempo de la historia transcurre en el presente, por lo que no es necesario diseñar una ciudad futurista y permite ahorrar los costosos gastos que ello generaría. Las Vegas, Los Ángeles o Nueva York se convierten en espacios protagonistas, todos ellos en clave de acción. En Minority Report, aunque ambientada en 2054, se reconoce Washington D.C. Por otro lado, son Asesinos cibernéticos y su secuela las que escogen un modelo postapocalíptico en un planeta lejano semidesierto en el que permanecen las ruinas y los búnkeres de la guerra.

La conclusión más clara del análisis de las adaptaciones de la obra de Dick es el carácter eminentemente violento que adquiere la ciudad: el espacio urbano es el escenario perfecto para que el héroe acometa sus hazañas y todos los elementos aparecen dispuestos para escenas de luchas, disparos, explosiones, huidas y carreras. La ciudad no es, por tanto, un lugar seguro, al menos para el protagonista, que debe vencer todos los obstáculos para culminar su objetivo, que en muchos casos no es otro que vencer a los malvados

11 Resulta muy aclaratoria la clasificación no exhaustiva que realizan Moreno y Palibrk, en la que describen brevemente las principales características de distintos tipos de ciudad prospectiva (2011: 124-130). 
y quedarse con la chica ${ }^{12}$. Una vez resuelto el conflicto -normalmente gracias al uso de la fuerza-, la seguridad vuelve a la ciudad, producto del final feliz. Es posible la utopía, como vemos en Marte tras la victoria en el combate final de Quaid, que libera a los habitantes del planeta rojo de la opresión a la que vivían sometidos.

Por tanto, el cine proyecta una imagen insegura de la ciudad para desarrollar películas de acción que puedan tener una recaudación satisfactoria. La presión de la industria hollywoodiense por lograr beneficios económicos permite que los proyectos cinematográficos puedan ser modificados para tratar de conseguir acercarse al público más amplio posible, aunque esto vaya en contra de la originalidad y de la capacidad de innovación, y por ello los modelos urbanos que se han utilizado son mayoritariamente los de películas de acción.

\section{Bibliografía}

BOU, Núria; y PÉREZ, Xavier (2000): El tiempo del héroe: épica y masculinidad en el cine de Hollywood. Barcelona: Paidós.

CHIMAL, Alberto (2005): "Los relatos de Philip K. Dick en el cine". El Cuentoen Red: Estudios sobre la Ficción Breve, núm. 12, pp. 89-107.

DICK, Philip K. (2005): "La paga", en Cuentos Completos, vol. I, pp. 326361. Barcelona: Minotauro.

- (2006): Una mirada a la oscuridad. Barcelona: Minotauro.

- (2007): "El hombre dorado", en Cuentos Completos, vol. III, pp. 46-76. Barcelona: Minotauro.

- (2011): "Equipo de ajuste", en Cuentos Completos, vol. II (edición actualizada), pp. 350-373. Barcelona: Minotauro.

MORENO, Fernando Ángel; y PALIBRK, Ivana (2011): "La ciudad prospectiva" [en línea]. En: Ángulo Recto. Revista de estudios sobre la ciudad como espacio plural, vol. 3, núm. 2, pp. 119-131. En: http://www.ucm.es/info/angulo/volumen/Volumen03-2/varia01.htm. ISSN: 1989-4015. DOI: http://dx.doi.org/10.5209/rev ANRE.2011.v3.n2.375844.

RIVERO GRANDOSO, Javier (2011): "Utopías urbanas en la ciencia ficción: textos literarios y su adaptación al cine", en Eugenia Popeanga (coord.), Ciudades mito: modelos urbanos culturales en la literatura de viajes y en la ficción, pp. 271-286. Bern: Peter Lang.

VILLARRUBIA JIMÉNEZ-MOMEDIANO, Arturo (2010): "Cine y literatura de ciencia ficción: crónica de un divorcio", en Pilar Andrade, Arno Gimber y María Goicoechea (eds.), Espacios y tiempos de lo fantástico: Una mirada desde el siglo XXI, pp. 271-278. Bern: Peter Lang.

12 Como ya comentamos, A Scanner Darkly no es una película de acción y tampoco se nutre de los clichés cinematográficos, pero, como el resto, también presenta una ciudad insegura por la expansión del consumo de drogas. Esta percepción es mayor desde la óptica paranoica de los consumidores de la Muerte Lenta. 


\section{Filmografía}

LINKLATER, Richard (dir.) (2006): A Scanner Darkly. Estados Unidos: Warner Independent Pictures.

NOLFI, George (dir.) (2011): The Adjustment Bureau. Estados Unidos: Universal Pictures.

TAMAHORI, Lee (dir.) (2007): Next. Estados Unidos: Paramount Pictures.

WILSON, Sheldon (dir.) (2009): Screamers: The Hunting. Canadá: Pope Productions.

WISEMAN, Len (dir.) (2012): Total Recall. Estados Unidos: Columbia Pictures.

WOO, John (dir.) (2003): Paycheck. Estados Unidos: Paramount Pictures. 